\section{Framework for Blockchain Implementation to Trace the Vietnam Dairy Supply Chain}

\author{
Nguyen Thi Nha Trang ${ }^{1}$ and Albert W K Tan ${ }^{2}$ \\ ${ }^{1}$ Department of Logistics and Supply Chain Management, Faculty of Eco- \\ nomics, Vietnam Maritime University, Vietnam
}

${ }^{2}$ Malaysia Institute for Supply Chain Innovation, Malaysia

\section{Introduction}

To protect human health, it is essential for foods to be manufactured, processed, transported and stored safely. However, many studies have revealed that every year around six hundred million people in the world are affected by diseases due to the consumption of contaminated food and more than forty thousand lives are lost annually for the same reason ${ }^{1}$. As one of the most consumed food categories all over the world, global dairy industry today is worth over $\$ 400$ billion, representing around $14 \%$ of global agricultural trade with milk being the third most produced agriculture commodity ${ }^{2}$. Despite being consumed regularly by many people, they are highly vulnerable to health issues such as infants or pensioners due to many quality problems. In this context, traceability is widely recognized as a requisite to meet the urgent need of food safety and quality. Using transparency as a foundation, supply chain traceability enables the access to critical information about origins of a raw material or a finished product and the processes that it underwent [1]. Nevertheless, with rising sophistication level of food frauds, the existing traceability systems for dairy products in developing countries such as Vietnam are inadequate and seemingly far outstripped by developed countries. This fact has raised the concerns about the applications of advanced technologies such as blockchain to narrow the food quality gaps in developing countries.

Blockchain is an emerging technology that has been gaining a lot of attentions and expected to become the one transforming businesses across different industries [2]. One promising feature of blockchain

${ }^{\overline{ }}$ Corresponding author: Albert W K Tan, Malaysia Institute for Supply Chain Innovation, Malaysia, E-mail: atan@misi.edu.my

Citation: Trang NTN, Tan AWK (2020) Framework for Blockchain Implementation to Trace the Vietnam Dairy Supply Chain. J Dairy Res Tech 3: 023.

Received: November 07, 2020; Accepted: November 27, 2020; Published: December 04, 2020

Copyright: (c) 2020 Trang NTN, et al. This is an open-access article distributed under the terms of the Creative Commons Attribution License, which permits unrestricted use, distribution, and reproduction in any medium, provided the original author and source are credited.

${ }^{1}$ According to the annual report of World Health Organization (WHO) in 2017 ${ }^{2}$ According to the annual report of Food and Agriculture Organization of the United Nations (FAO) in 2016 is to provide transparency, which supports traceability in ways that older technologies cannot reach. Thus, it has been studied and applied as a solution to tackle food safety issues in supply chains. Based on the secondary data gathered from multiple sources and the analysis of a case, a research is conducted in Vietnam with the aim at answering the research question: How can blockchain help to address the food safety issues in Vietnamese domestic dairy sector? The paper will share the findings from the study and propose a new framework using blockchain to improve the traceability of dairy products.

\section{Literature Review}

\section{Traceability in supply chain}

Multiple approaches have been applied for supply chain traceability, ranging from traditional paper-based ones to sophisticated and advanced technologies [3]. However, less developed countries tend to favor recording documents rather than leveraging cutting-edge techniques to perform traceability in food supply chain [4]. Berman B, et al., [5] argue that most of Chinese farmers are not familiar even with recording documents and exchanging them with wholesalers who will buy their products, let alone participating in a complex computer-based system. Also, there are not many applications developed specifically for traceability since companies prefer to use their integrated information system like ERP to avoid overspending [6].

\section{Blockchain applications in food traceability}

Blockchain is defined as a decentralized and distributed ledger system that can store or record data and transactions backed by cryptographic value [7]. Blockchain can be characterized through five principles: security [8], peer-to-peer transmission [9], transparency with pseudonymity [10], irreversibility of records [11] and computational logic [12]. The idea of a blockchain based traceability system was first introduced [13]. The subsequent years witnessed many projects in which blockchain was used by a UK-based company named Provenance to track the origin of fishes [14], and by Walmart and IBM to develop traceability solutions for pork in China and mangos in the US [15]. The systems were completely "end-to-end" with information tracked going far beyond origin of products, including storage temperatures, shipping details, batch number and so on. Some other technologies such as Internet of Things (IoT) have also been integrated with blockchain to improve the efficiency of food traceability system [16] in the hope of building an open and comprehensive network of devices that can automatically organize and share resources and data [17]. Today, blockchain has much potential to become a realistic technological option to address the challenge in mining and managing information across the supply chain. This concept is further reinforced through many relevant standards such as ISO 22739:2020 that defines basic terms relating to blockchain and distributed ledger technologies to clarify the meaning of terms and concepts used in other document within the domain of ISO standards. In addition, ISO 22005:2007 provides general principles and basic requirements for the design and implementation for a feed and food traceability system. 


\section{Research Methodology}

The main goal of this study is to identify the potential roles of blockchain technology to overcome food safety issues in Vietnam's domestic dairy sector. Secondary data are gathered from multiple sources and presented in three forms: statistical, graphical data and tabulated form. It is considered as reasonable to use the evidences verified in the previous literature, especially in the complex areas that have not been substantially researched [18]. The data analyses will serve as a foundation to propose a conceptual framework that is expected to answer the research question: How can blockchain help address the food safety issues in the Vietnamese domestic dairy sector?

\section{Data Collection and Analysis}

\section{Dairy food in Vietnam}

Dairy is one of the most consistently growing industries in Vietnam. According to Thuy NTD et al., [19], the sector recorded revenue of US\$4.4 billion in 2017, a ten percent increase compared to 2016. Liquid and powdered milk are the most consumed dairy segments in Vietnam, occupying over 65 percent of the market, followed by yogurt and condensed milk, representing 14 and 8.3 percent respectively. Although dairy products rank third in the number of food frauds in Vietnam, there is little evidence of any existing dairy traceability system in the country, according to a co-founder off TE Food, a Vietnam software company. It is noteworthy that in most cases, Vietnamese dairy companies have not been subject to any legal liability for their defective products, with the incident occurred in 2018 as an example when more than 70 primary students in Dong Nai were poisoned after drinking the milk products manufactured by Nuti food company. But everyone is not accepting the faults for these food quality issues and turns the blames towards the transportation or storage operators or even the customers.

\section{A Proposed Framework for Adopting Blockchain to Dairy Supply Chain Traceability}

In order to over the food quality issues, we are proposing a new framework for traceability as shown in figure 1 for the Vietnamese domestic dairy supply chain, making use of blockchain, IoT and smart contracts. The framework is a result of the knowledge gained from industry inputs and from the recent literature. The blockchain-based traceability system can be explained in five stages of a dairy supply chain, namely 1) At the farm, 2) Transporting, 3) Processing plant, 4) Distribution and 5) at the retailers.

\section{At the farm}

Farmers will activate QR codes printed on removable paper-based label stickers attached to milk churns with the help of smart phone's scanning applications before milking process takes place. The data of corresponding milking cattle, including cattle breed, vaccines, feeds and animal health will be updated to blockchain and become infeasible to tamper with. Traceability begins at the phase of raw milk collection. If any milk churn is not able to meet initial requirements and thus rejected by milk collectors, the farmer will identify exactly the cow that produce the rejected milk by scanning the QR code on the returned churn. At the initial phase of raw milk production, the Hazard Analysis Critical Control (HACCP) system ${ }^{3}$ can help to enhance

${ }^{3} \mathrm{HACCP}$ is a management system in which food safety is addressed through the analysis and control of biological, chemical, and physical hazards from raw material production, procurement and handling, to manufacturing, distribution and consumption of the finished product.

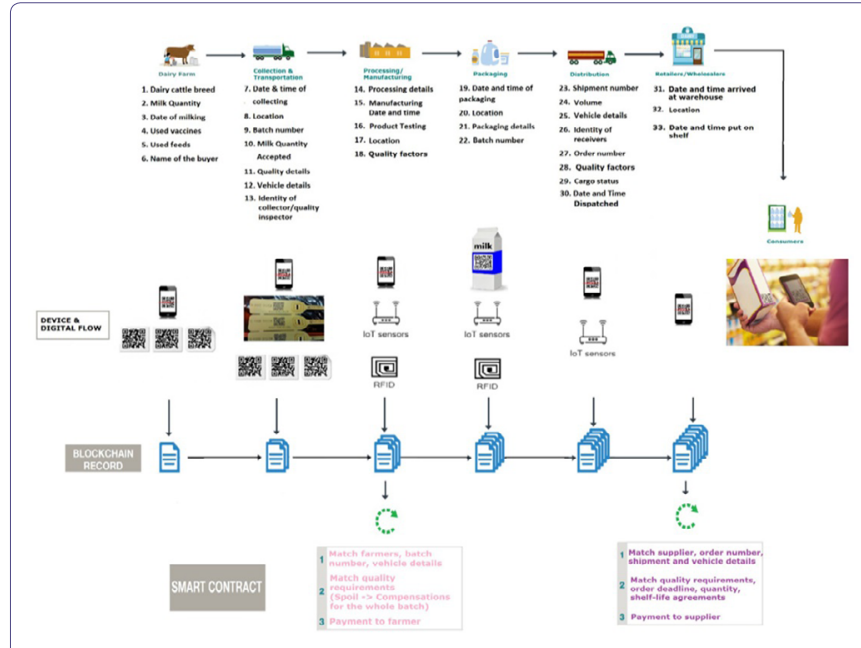

Figure 1: Framework for a blockchain traceability system for dairy supply chain,

the safety of milk and dairy products will help analyze and control potential risks through the critical hygienic milking measures. Normally, the farm milking process in Vietnam can be executed manually or with the aid of milking machines. In this way, related information of milking procedures can be traced back and understood with the help of QR code and blockchain, such as whether the cows have been healthy, who was the person in performing the milking for this batch of cows, which milking machine was used, if milking and storage equipment were cleaned correctly, etc. In case approved milk churns are consolidated in a giant tank and then a milk tanker truck, the applications of QR codes and blockchain to record information remain unchanged.

With a new QR code security seal attach to the truck (Figure 2), milk collectors can upload all information associated with milk batch number, collecting time and location, original farms, total milk volume and proportion contributed by farms/cows, initial tests' results and transportation vehicle details to the distributed ledger using blockchain. In addition, a smart contract with terms and conditions coded and stored in a blockchain can be applied to automate transactions between farmers and manufacturers. Lead time can become an indicator in contract to evaluate the delivery reliability of suppliers at the farm location. IoT sensors are used to monitor and record the quality criteria such as temperature during farmers' raw milk shipping process to the collector or right after the production at the farm. IOT sensors can indicate deviations from the proper storage temperature throughout the flow of raw milk from farms to processing plants. It is the most ideal, according to the quality standards for milk and dairy products defined by ISO standard, that raw milk must be processed or poured into a refrigerated tank within one hour of milking. Cooling the milk down to $4^{\circ} \mathrm{C}$ or less is an effective method of controlling the growth of micro-organisms. In developing countries like Vietnam, milk production remains small- scale and scattered. The amount of milk collected by farm households or farms is modest. Additionally, it is uneconomical for families or farm owners to equip themselves with modern refrigeration facilities. Consequently, to prolong the safe time of milk while waiting to be transported to milk collection and cooling centers or dairy plants, a simple method of cold storage can be used as soaking the whole milk churns (carefully capped) in a tank containing ice or cold water. It is thus necessary to equip all milk tanks with IoT 
thermal sensors, or more simple low-cost devices like Time Temperature Indicator (TTI) whose accumulated time-temperature history of milk can be subsequently recorded to immutable digital ledger system of blockchain.

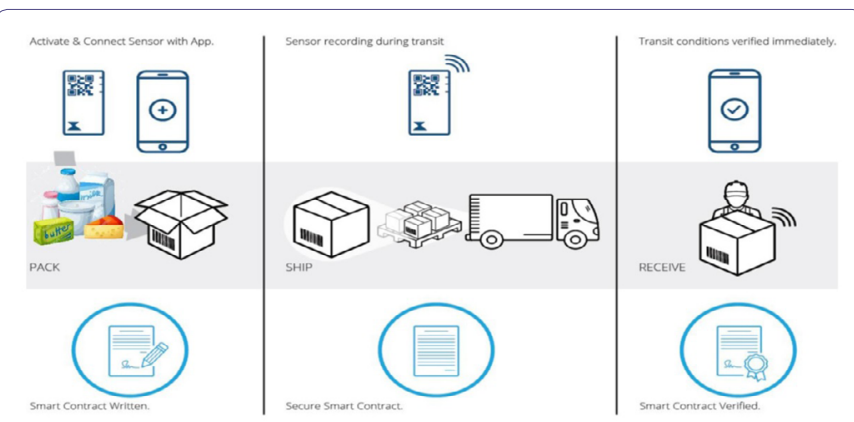

Figure 2: Smart contract between dairy firms and partners in the supply chain.

\section{Transporting}

At the second stage, when the truck carrying raw milk arrives at processing factory, the worker will scan the seal and access the data that have been manually inputted by farmers and collectors. The worker is thus able to verify and accept the shipment while the scan is logged and the status of milk batch is updated to blockchain. To support double testing raw milk by dairy firms, collectors can remove the QR code attach on milk churns and attach it to the jars that contain sample milk drawn from respective chunks earlier within the collection process. ISO/TC 34/SC 5 (https://www.iso.org/committee/47878.html) sampling method can be adopted to cover the diary chain from production to consumption. If a quality issue is detected during sampling, the inspectors at processing premises can trace back to a group of cows where their milks are mixed together and farms from the scanned QR codes. The farmers found with of substandard raw milk will compensate to the milk producers. A smart contract between parties is therefore necessary at this stage.

\section{At the processing plant}

At the third stage, raw milk is transformed into finished items such as liquid milk products, yogurt, cheese, butter and creams, after going through many processing steps such as pasteurization, homogenization, further manufacturing, packaging and storage. Blockchain system, sensors and QR codes are executed similarly to deliver the most accurate information of farms, collectors, details of milk processing, expiry date, etc., not only to dairy manufacturers but also to end customers. The integration of these technologies with existing internal business application software such as Enterprise Resource Planning (ERP) or Warehouse Management System (WMS) helps to improve the accuracy of information updated to the blockchain.

\section{At the distribution center}

At the stage of distribution, the cargo handler will perform a similar practice as the raw milk collector by scanning and grouping finished products into batches. Instead of chunks or trucks, QR codes will be pinned against boxes or pallets that convey bottled and packaged dairy products. A smart contract, combined with IoT sensors, is highly recommended for the transactions between dairy companies and wholesalers/retailers to reduce transaction time. Before the delivery, the logger ID of sensors, shipment details, and criteria such as temperature, humidity, shelf-life, and order deadline are updated and validated against the smart contract. Sensors, for instance, can detect the failures of temperature or humidity during the transportation. The receiver subsequently can verify the shipments when the trucks reach. Retailers or wholesalers also need to scan $\mathrm{QR}$ codes on each product, pallet, box or truck so that the status of products can be added to blockchain and consumers can access the origin of the milk products.

\section{At the retailers}

Ultimately, the end consumers can download the User Interface Module of the application via App Stores on their smart phone and use it to scan the QR code on the product at the Point of Sale (POS) and check its provenance as well as authenticity. They will be redirected to a webpage containing information that could answer the following questions about a particular dairy item:

- What farm did the raw milk used to manufacture this item come from?

- When and where was the item manufactured? What processes did this product go through? What are the food safety standards that the supply chain followed when manufacturing this product (HACCP, ISO, national standards)?

- What date and time did this product reach the retailer and appear on this shelf? What is the expiration date of this product?

However, besides supermarkets, convenience stores and other comparable retailers, dairy products in Vietnam are sold in a lot of small grocery stores that usually lack standard technologies or even POS system to scan QR codes on purchased products to update their status. Consequently, this feature is not realistic enough to be applied for the whole supply chain in Vietnam. If dairy sale channel scan become consistent in terms of equipment and technologies in the future, it can certainly be extended into future software features.

\section{Conclusion}

The proposed framework for adopting blockchain to dairy supply chain traceability can bring benefits to different supply chain members in many ways. Farmers are guaranteed with the payments automatically done right after all terms and conditions of smart contracts are transparently met. Another benefit is to eliminate human errors caused by conventional dairy farmers in Vietnam when carrying out critical activities. Consumers now have a platform to prove the authenticity of dairy products and regain the trust. With sensors and smart contracts are integrated to the system, businesses can save significant time and costs for human resources or intermediaries. Besides, manufacturers can be more assured that the standard procedures will be strictly followed by farmers since this traceability system can trace back to a particular batch of milk coming from a group of cows. Food wastage caused by the perish ability of both raw milk and finished dairy merchandise is also reduced thanks to improved speed of handling goods.

In the long run, the dairy traceability system can help the dairy firms to operate more effectively and deliver higher service levels to the downstream stakeholders. Any failure of conforming to quality and safety standards from upstream parties will be detected and seen through the system. The government can rely on the proposed traceability solution with transparency, convenience and more importantly, 
a realistic system to solve dairy safety issues and frauds with limited risks of human errors and being tampered during the information exchange.

\section{Limitations and Future Research}

Future projects can further research on dairy industry by developing traceability system for import and export instead of for only domestic market like this paper. Traceability for other processed food items includes meat, fruits, eggs, vegetables and seafood.

\section{References}

1. Francisco K, Swanson D (2018) The Supply Chain Has No Clothes: Technology Adoption of Blockchain for Supply Chain Transparency. Logistics 2: 2 .

2. Woodside JM, Augustine FK, Giberson W (2017) Blockchain Technology Adoption Status and Strategies. Journal of International Technology and Information Management 26: 65-93.

3. Wang X, D Li (2006) Value Added on Food Traceability: A Supply Chain Management Approach. In 2006 IEEE International Conference on Service Operations and Logistics, and Informatics, 493-498.

4. Bello LL, Mirabella O, Torrisi N (2005) A General Approach to Model Traceability Systems in Food Manufacturing Chains. In 2005 IEEE Conference on Emerging Technologies and Factory Automation 2: 8.

5. Barry B, Swani K (2010) Managing Product Safety of Imported Chinese Goods. Business Horizons 53: 39-48.

6. Wognum PM, Bremmers H, Trienekens JH, van der Vorst JGAJ, Bloemhof JM (2011) Systems for Sustainability and Transparency of Food Supply Chains - Current Status and Challenges. Advanced Engineering Informatics 25: 65-76.

7. Dutta P, Choi TM, Somani S, Butala R (2020) Blockchain Technology in Supply Chain Operations: Applications, Challenges and Research Opportunities. Transportation Research Part E: Logistics and Transportation Review 142: 102067.
8. Louise VL (2016) Trusting Records: Is Blockchain Technology the Answer? Records Management Journal 26: 110-139.

9. Satoshi N (2008) Bitcoin: A Peer-to-Peer Electronic Cash System. In Satoshi Nakamoto Institute 1-9.

10. Iansiti M, Lakhani KR (2017) The Truth about Blockchain. Havard Business Review 2017: 1-11.

11. Zhang P, White J, Schmidt DC, Lenz G (2017) Applying Software Patterns to Address Interoperability Challenges in Blockchain-Based Healthcare Apps. In ArXiv Preprint.

12. Catalini C (2017) How Blockchain Technology Will Impact the Digital Economy. MIT IDE Research Brief 5: 1-4.

13. Bateman AH (2015) Innovation Strategies: Tracking the Value of Traceability. MIT Center for Transportation and Logistics 19: 8-10.

14. Levitt T (2016) Blockchain Technology Trialled to Tackle Slavery in the Fishing Industry. The Guardian.

15. Kamath T (2018) Food Traceability on Blockchain: Walmart's Pork and Mango Pilots with IBM. The JBBA 1: 1-12.

16. Tian F (2016) An Agri-Food Supply Chain Traceability System for China Based on RFID Blockchain Technology. In $201613^{\text {th }}$ International Conference on Service Systems and Service Management (ICSSSM), 1-6.

17. Madakam S, Ramaswamy R, Tripathi S (2015) Internet of Things (IoT): A Literature Review. Journal of Computer and Communications 3: 164-173.

18. Ellram LM (1996) The Use of the Case Study Method in Logistics Research. Journal of Business Logistics 17: 93-138.

19. Thuy NTD, Thu NT, Cuong NH, Ty LV, NguyenTTB, et al. (2018) Polymorphism of PIT-1 and Prolactin Genes and Their Effects on Milk Yield in Holstein Frisian Dairy Cows Bred in Vietnam. Animal Genetics 54: 346352. 


\section{H}

Advances In Industrial Biotechnology | ISSN: 2639-5665

Advances In Microbiology Research | ISSN: 2689-694X

Archives Of Surgery And Surgical Education | ISSN: 2689-3126

Archives Of Urology

Archives Of Zoological Studies | ISSN: 2640-7779

Current Trends Medical And Biological Engineering

International Journal Of Case Reports And Therapeutic Studies | ISSN: 2689-310X

Journal Of Addiction \& Addictive Disorders | ISSN: 2578-7276

Journal Of Agronomy \& Agricultural Science | ISSN: 2689-8292

Journal Of AIDS Clinical Research \& STDs | ISSN: 2572-7370

Journal Of Alcoholism Drug Abuse \& Substance Dependence | ISSN: 2572-9594

Journal Of Allergy Disorders \& Therapy | ISSN: 2470-749X

Journal Of Alternative Complementary \& Integrative Medicine | ISSN: 2470-7562

Journal Of Alzheimers \& Neurodegenerative Diseases | ISSN: 2572-9608

Journal Of Anesthesia \& Clinical Care | ISSN: 2378-8879

Journal Of Angiology \& Vascular Surgery | ISSN: 2572-7397

Journal Of Animal Research \& Veterinary Science | ISSN: 2639-375

Journal Of Aquaculture \& Fisheries | ISSN: 2576-5523

Journal Of Atmospheric \& Earth Sciences | ISSN: 2689-8780

Journal Of Biotech Research \& Biochemistry

Journal Of Brain \& Neuroscience Research

Journal Of Cancer Biology \& Treatment | ISSN: 2470-7546

Journal Of Cardiology Study \& Research | ISSN: 2640-768X

Journal Of Cell Biology \& Cell Metabolism | ISSN: 2381-1943

Journal Of Clinical Dermatology \& Therapy | ISSN: 2378-8771

Journal Of Clinical Immunology \& Immunotherapy | ISSN: 2378-8844

Journal Of Clinical Studies \& Medical Case Reports | ISSN: 2378-880

Journal Of Community Medicine \& Public Health Care | ISSN: 2381-1978

Journal Of Cytology \& Tissue Biology | ISSN: 2378-9107

Journal Of Dairy Research \& Technology | ISSN: 2688-9315

Journal Of Dentistry Oral Health \& Cosmesis | ISSN: 2473-6783

Journal Of Diabetes \& Metabolic Disorders | ISSN: 2381-201X

Journal Of Emergency Medicine Trauma \& Surgical Care | ISSN: 2378-8798

Journal Of Environmental Science Current Research | ISSN: 2643-5020

Journal Of Food Science \& Nutrition | ISSN: 2470-1076

Journal Of Forensic Legal \& Investigative Sciences | ISSN: 2473-733X

Journal Of Gastroenterology \& Hepatology Research | ISSN: 2574-2566
Journal Of Genetics \& Genomic Sciences | ISSN: 2574-2485

Journal Of Gerontology \& Geriatric Medicine | ISSN: 2381-8662

Journal Of Hematology Blood Transfusion \& Disorders | ISSN: 2572-2999

Journal Of Hospice \& Palliative Medical Care

Journal Of Human Endocrinology | ISSN: 2572-9640

Journal Of Infectious \& Non Infectious Diseases | ISSN: 2381-8654

Journal Of Internal Medicine \& Primary Healthcare | ISSN: 2574-2493

Journal Of Light \& Laser Current Trends

Journal Of Medicine Study \& Research | ISSN: 2639-5657

Journal Of Modern Chemical Sciences

Journal Of Nanotechnology Nanomedicine \& Nanobiotechnology | ISSN: 2381-2044

Journal Of Neonatology \& Clinical Pediatrics | ISSN: 2378-878X

Journal Of Nephrology \& Renal Therapy | ISSN: 2473-7313

Journal Of Non Invasive Vascular Investigation | ISSN: 2572-7400

Journal Of Nuclear Medicine Radiology \& Radiation Therapy | ISSN: 2572-7419

Journal Of Obesity \& Weight Loss | ISSN: 2473-7372

Journal Of Ophthalmology \& Clinical Research | ISSN: 2378-8887

Journal Of Orthopedic Research \& Physiotherapy | ISSN: 2381-2052

Journal Of Otolaryngology Head \& Neck Surgery | ISSN: 2573-010X

Journal Of Pathology Clinical \& Medical Research

Journal Of Pharmacology Pharmaceutics \& Pharmacovigilance | ISSN: 2639-5649

Journal Of Physical Medicine Rehabilitation \& Disabilities | ISSN: 2381-8670

Journal Of Plant Science Current Research | ISSN: 2639-3743

Journal Of Practical \& Professional Nursing | ISSN: 2639-568

Journal Of Protein Research \& Bioinformatics

Journal Of Psychiatry Depression \& Anxiety | ISSN: 2573-0150

Journal Of Pulmonary Medicine \& Respiratory Research | ISSN: 2573-0177

Journal Of Reproductive Medicine Gynaecology \& Obstetrics | ISSN: 2574-2574

Journal Of Stem Cells Research Development \& Therapy | ISSN: 2381-2060

Journal Of Surgery Current Trends \& Innovations | ISSN: 2578-7284

Journal Of Toxicology Current Research | ISSN: 2639-3735

Journal Of Translational Science And Research

Journal Of Vaccines Research \& Vaccination | ISSN: 2573-0193

Journal Of Virology \& Antivirals

Sports Medicine And Injury Care Journal | ISSN: 2689-8829

Trends In Anatomy \& Physiology | ISSN: 2640-7752

Submit Your Manuscript: https://www.heraldopenaccess.us/submit-manuscript 